\title{
Vivências nas Medidas Socioeducativas: Possibilidades para o Projeto de Vida dos Jovens
}

\author{
Cibele Soares da Silva Costa ${ }^{1}$ \\ ${ }^{1}$ Universidade Federal da Paraíba, PB, Brasil. \\ Maria de Fatima Pereira Alberto ${ }^{2}$ \\ Erlayne Beatriz Félix de Lima Silva ${ }^{3}$ \\ ${ }^{3}$ Universidade Federal da Paraíba, PB, Brasil.
}

Resumo: Este artigo tem como objetivo analisar as implicações das vivências de jovens em cumprimento de medidas socioeducativas para a construção do projeto de vida. Esse estudo tem como aporte a Psicologia Histórico-Cultural de Vigotski. Participaram da pesquisa dez jovens, com idades entre 15 e 17 anos, que cumpriam medida socioeducativa de internação em um município paraibano. Utilizou-se uma entrevista aberta e os dados foram submetidos à Análise Temática de Conteúdo, destacando-se as categorias: atividades realizadas no cotidiano do cumprimento da medida socioeducativa, participação da família, relações dos jovens com os profissionais, vivências significativas durante o cumprimento da medida socioeducativa e planos para o futuro. Os dados apontaram que os jovens esboçam seus projetos de vida a partir da expectativa de conclusão dos estudos, da formação e inserção profissional, do retorno à convivência familiar e constituição de sua própria família. No entanto, as instituições de medidas socioeducativas não têm garantido esses elementos de forma suficiente para promover o desenvolvimento e a autonomia dos jovens, por meio de um conjunto de ações articuladas e pautadas em uma função pedagógica, mas que ainda centram suas atividades em procedimentos de caráter burocrático e práticas punitivas. Considera-se que as unidades de medidas socioeducativas devem pautar suas intervenções na efetivação da socioeducação dos jovens a partir da perspectiva da garantia de direitos e da oferta de ações que promovam a construção de projetos de vida.

Palavras-chave: Juventude, Projeto de vida, Medidas Socioeducativas. 


\title{
Experiences in Socio-educational Measures: Possibilities for Young People's Project of Life
}

\begin{abstract}
This article aims to analyze the implications of the experiences of young people who are in compliance with socio-educational measures for the construction of their life projects. This study is supported by Vygotsky's Historical-Cultural Theory. Ten young people between the ages of 15 and 17 who underwent socio-educational measures with freedom restraint in a municipality of Paraíba participated in the study. An interview was used and data were submitted to Content Thematic Analysis, revealing the categories: activities carried out in the daily life while complying with the socio-educational measure, family participation, youth relations with professionals, significant experiences during the socio-educational measure, and plans for the future. Data showed that young people see their life projects from the expectation of completing their studies, getting their professional formation and insertion, returning to family life and constituting their own family. However, the socio-educational institutions do not guarantee these elements sufficiently to promote the development and autonomy of young people, through a set of actions articulated and based on a pedagogical function. These still focus their activities on bureaucratic procedures and punitive practices. It is considered that the units of socio-educational measures should guide their interventions in the realization of the socio-education of youth from the perspective of the guarantee of rights and the offer of actions that promote the projects of life.
\end{abstract}

Keywords: Youth, Life project, Socio-educational measures.

\section{Vivencias en las Medidas Socioeducativas: Posibilidades para el Proyecto de Vida de los Jóvenes}

Resumen: Este artículo tiene como objetivo analizar las implicaciones de las vivencias de jóvenes en cumplimiento de medidas socioeducativas para la construcción del proyecto de vida. Este estudio tiene como aporte la Teoría Histórico-Cultural de Vigotski. Participaron de la investigación diez jóvenes, con edades entre 15 y 17 años, que cumplían una medida socioeducativa de internación en un municipio del estado de Paraíba (Brasil). Se utilizó una entrevista abierta y los datos fueron sometidos a Análisis de Contenido Temático, destacándose las categorías: actividades realizadas en el cotidiano del cumplimiento de la medida socioeducativa, participación de la familia, relaciones de los jóvenes con los profesionales, vivencias significativas durante el cumplimiento de la medida socioeducativa, planes para el futuro. Los datos apuntaron que los jóvenes esbozan sus proyectos de vida a partir de la expectativa de conclusión de los estudios, de la formación e inserción profesional y del retorno a la convivencia familiar y constitución de su propia familia. Sin embargo, las instituciones de medidas socioeducativas no han garantizado esos elementos de forma suficiente para promover

el desarrollo y la autonomía de los jóvenes a través de un conjunto de acciones articuladas y pautadas en una función pedagógica. Todavía ellas centran sus actividades en procedimientos de carácter burocrático y prácticas punitivas. Se considera que las unidades de medidas socioeducativas deben pautar sus intervenciones en la efectividad de la socioeducación de los jóvenes desde la perspectiva de la garantía de derechos y de la oferta de acciones que promuevan la construcción de los proyectos de vida.

Palabras clave: Juventud, Proyecto de vida, Medidas Socioeducativas. 


\section{Introdução}

Este artigo tem como objetivo analisar as implicações das vivências de jovens em cumprimento de medidas socioeducativas para a construção de seus projetos de vida. Para isso, foi realizada uma pesquisa com jovens que estavam cumprindo medida socioeducativa de internação em um município do estado da Paraíba.

Nesse artigo, será considerado o termo jovem, partindo-se da concepção de juventude como construção social, histórica, cultural e relacional, que compreende a dimensão do ciclo vital entre a infância e a maturidade, marcada culturalmente pela realização de projetos de vida. Parte-se da perspectiva teórica da Psicologia Histórico-Cultural de Vigotski, que apesar de não ter definido o conceito de juventude, definiu as bases para o estudo do desenvolvimento humano, considerando os aspectos culturais e sociais na constituição dos sujeitos. Essa concepção afasta-se da visão naturalista que concebe o desenvolvimento a partir de fases universais, e considera que as mudanças correspondem aos avanços no desenvolvimento das funções psicológicas superiores, estando culturalmente relacionadas aos elementos da educação, formação profissional, trabalho e desenvolvimento da autonomia (Abrantes, \& Bulhões, 2016).

As medidas socioeducativas (MSE) são aplicadas aos jovens, a quem foram atribuídas a autoria de atos infracionais que estão determinadas no Estatuto da Criança e do Adolescente (ECA) (Lei No 8.069, 1990), podendo ser: advertência, obrigação de reparar o dano, prestação de serviços à comunidade, liberdade assistida, inserção em regime de semiliberdade e internação em estabelecimento educacional. Estas são regulamentadas pela Lei n. 12.594 (2012), que institui o Sistema Nacional de Atendimento Socioeducativo (Sinase), tendo por objetivos: promover a responsabilização dos jovens sobre as consequências do ato infracional, realizar a desaprovação da conduta infracional e proporcionar a integração social do jovem e a garantia de seus direitos individuais e sociais através da elaboração e do cumprimento do Plano Individual de Atendimento (PIA).

O Sinase regulamenta o atendimento ao jovem autor de ato infracional, por meio de um conjunto de princípios, regras e critérios para a execução das medidas socioeducativas, considerando parâmetros arquitetônicos das unidades e diretrizes pedagógicas para seu funcionamento. Enquanto sistema, o Sinase determina o princípio da incompletude institucional, o qual estipula a integração com as demais políticas públicas de educação, saúde, assistência social, cultura, lazer, esporte e capacitação para o trabalho, os quais devem estar definidos no Plano Individual de Atendimento, tanto para os jovens como para seus familiares, de modo a promover a sua participação e atender as suas necessidades (Alencar, 2014).

Desse modo, a efetivação do princípio da incompletude institucional depende da articulação das instituições que compõem o Sistema de Garantia de Direitos (SGD) por meio da intersetorialidade das políticas públicas e de um conjunto diversificado de atores que constituem as equipes multiprofissionais, sendo estas, compostas por pedagogos, psicólogos, assistentes sociais e advogados, profissionais da saúde, orientadores educacionais e agentes socioeducativos. Cada um desses atores exerce uma função fundamental no auxílio aos jovens em cumprimento de MSE, pois devem oferecer o atendimento diversificado de acordo com as necessidades destes, objetivando o acesso aos direitos previstos no ECA e incentivando o exercício da cidadania, por intermédio de um conjunto de ações cuja natureza tem por base o caráter sancionatório e pedagógico (Veronese, 2015).

No entanto, alguns autores identificaram obstáculos para a efetivação da socioeducação, entre eles, destacaram-se dificuldades referentes à não efetivação das garantias de direitos nas instituições de MSE e a fragmentação do atendimento das políticas sociais (Paiva, \& Cruz, 2014). Além desses aspectos, foram identificados entraves no que se refere a atuação dos profissionais nas unidades de medida socioeducativa, como formação limitada ou inadequada para esses espaços, em que há o predomínio de atividades de caráter clínico-individual e dificuldades em redirecionar suas práticas com base no atendimento socioeducativo (Paiva, \& Cruz, 2014; Morais, \& Malfitano, 2013; Santos, \& Menandro, 2017).

As MSE são caracterizadas por sua dupla dimensão, afirmando, de um lado, a responsabilização do jovem pelo ato infracional praticado, executada mediante a aplicação de medidas de restrição ou privação da sua liberdade; e, de outro lado, a existência de um conjunto de atividades de caráter pedagógico, nas quais devem ser priorizadas ações socioeducativas (Costa, 2015). Oliveira, Oliva, Arraes, Galli, Amorim e Stemler, (2015) discutem que o termo socioeducativo corresponde a uma mudança paradigmática introdu- 
zida pelo ECA às medidas atribuídas aos jovens, orientando ações cujo objetivo seria o de promover direitos e minimizar o efeito punitivo das MSE. No entanto, esses autores questionam a ausência de definição teórica do conceito socioeducativo no ECA e, posteriormente, na Lei do Sinase, analisando que, embora estes dispositivos representem avanços significativos na afirmação dos direitos das crianças e adolescentes e na aplicação de medidas aos jovens a quem são atribuídas a autoria de atos infracionais, no entanto, tais instrumentos normativos não definiram os tipos de ações a serem desenvolvidas de modo a promover o desenvolvimento dos jovens (Oliveira et al., 2015).

Em relação às MSE de privação de liberdade, Souza e Costa (2012), ao investigarem o significado que os jovens atribuem ao cumprimento da medida socioeducativa de internação, identificaram que a MSE não tem conseguindo produzir mudanças em suas vidas, sendo que a internação tem provocado nos jovens os sentimentos de raiva, revolta e mesmo o sentimento de injustiça, por se caracterizar como uma medida privativa de liberdade e, consequentemente, restringir direitos, apesar de ter a garantia de direitos sociais e individuais como um dos seus objetivos.

Por outro lado, esses e outros autores (Souza, \& Costa, 2012; Nardi, \& Dell'Aglio, 2013; Jimenez, \& Frasseto, 2014; Vicentin, 2016) têm identificado que, apesar dos aspectos apontados pelos jovens, as MSE de internação têm sido operadas como uma medida protetiva, por oferecer algumas garantias que lhes foram ausentes em suas histórias de vida, tais como acesso à escola, atendimento de saúde, oficinas pedagógicas, retirada de documentação pessoal, formação profissional; bem como por assumir uma função de proteção e preservação da vida, tendo em vista que alguns jovens sofrem ameaças de morte em seus territórios de origem. De acordo com Ferraz, Castro Junior, Vieira e Cordeiro (2011), tais ameaças estão relacionadas a motivos variados como: existência de dívidas com o tráfico de drogas, testemunho de crimes ou mesmo pelo fato de os jovens desejarem se desvincular do ato infracional.

No que se refere às garantias de direito ofertadas por meio do atendimento na internação, a formação profissional representa um dos aspectos colocados pelos jovens como algo positivo, sendo através da MSE que alguns deles conseguem acessar o direito à profissionalização (Teixeira, Oliveira, Guido, \& Barone, 2016). A capacitação para o trabalho está determinada no Sinase, de modo a compor a organização pedagógica institucional e contribuindo para o desenvolvimento pessoal e social do jovem. De acordo com Barone (2016), a capacitação para o trabalho de jovens em cumprimento de medidas socioeducativas deve incluir o desenvolvimento de competências e habilidades que considerem as demandas reais do mundo do trabalho de modo a promover a inserção futura dos jovens nos espaços de trabalho, articulado com os princípios educativos de formação cidadã e com a educação escolar.

No entanto, Barone e Silva (2015), discutem que, apesar da capacitação para o trabalho compor um dos eixos estruturantes do Sinase, essa oferta não vem ocorrendo em todas as unidades privativas de liberdade ou não são suficientes para atender a todos os jovens internos, além do fato de que em algumas unidades de internação há pouca variedade na oferta dos cursos profissionalizantes ou esses ocorrem de maneira esporádica, o que compromete a formação oferecida. Soma-se a isso o fato de os jovens, ao saírem das instituições de internação, enfrentarem dificuldades no acesso ao mercado formal de trabalho, seja pela pouca qualificação profissional e baixa escolaridade, ou pelo estigma que os tem acompanhado pelo cumprimento de uma medida socioeducativa (Ritter, 2010).

A profissionalização e a escolarização são significadas pelos jovens como a possibilidade de conseguirem uma colocação no mercado de trabalho e obter ascensão social e a desvinculação dos atos infracionais. Em suas histórias de vida, a escola se caracterizou como espaço excludente, repercutindo na evasão, sendo que, durante o cumprimento da MSE, deve ser viabilizado o retorno desses jovens à escola (Baquero, Lemes, \& Santos, 2011; Nardi, \& Dell'Aglio, 2013). No entanto, como discutem Oliveira, Voltolini e Costa (2016), as escolas das instituições de MSE não têm contribuído para o desenvolvimento dos jovens e para promover o exercício da cidadania, devido às dificuldades estruturais que se refletem na inadequação das salas de aula e dos recursos didáticos, problemas como a superlotação nas unidades de internação e o reduzido tempo de aula, recorrentes suspensões das aulas em razão da existência de rebeliões ou demais conflitos, à própria cultura de cárcere presente nas unidades de internação e a falta de qualificação dos profissionais que atuam nas escolas das unidades. 
Outro aspecto importante destacado pelos jovens é a participação da família durante o cumprimento da MSE. Essa participação é significada como fonte de apoio e apontada como motivação para a desvinculação da prática de atos infracionais (Yokomiso, 2013). Nesse sentido, Medeiros e Paiva (2015) discutem que os programas de MSE devem oferecer o suporte necessário às famílias, garantindo sua presença e participação no cotidiano das unidades, bem como realizando encaminhamentos para as demais políticas sociais. No entanto, essas autoras identificaram diversas violações à convivência familiar, entre estas, a precariedade no momento da visita, as humilhações vivenciadas pelos familiares, a falta de informações sobre o cumprimento da MSE e a inexistência de espaços físicos adequados para as visitas íntimas, que comprometem o fortalecimento dos vínculos familiares, tal como preconiza o Sinase (Medeiros, \& Paiva, 2015). Além de exercer a função de suporte para o cumprimento da medida socioeducativa, os jovens também fazem referência à família como elemento para seus projetos de vida, tanto pela constituição de sua própria família ou pela possibilidade de auxiliarem sua família de origem ao término da MSE (Melsert, \& Bock, 2015).

Nesse sentido, a literatura sobre os jovens em cumprimento de MSE mostra que estes começam a visualizar possibilidades de mudanças de vida e desvinculação dos atos infracionais a partir de um conjunto de elementos, tais como conclusão dos estudos, formação e inserção profissional, apoio da família e o auxílio da intervenção dos profissionais que compõem as diversas políticas públicas (Silveira, Machado, Zappe, \& Dias, 2015). Neste estudo, buscou-se analisar se as vivências oportunizadas durante o cumprimento da medida socioeducativa de internação têm possibilitado a construção de projetos de vida para os jovens.

Para analisar as implicações das vivências dos jovens em cumprimento de MSE para a construção do projeto de vida, utilizou-se a Psicologia Histórico-Cultural de Vigotski. Nessa teoria, compreende-se que o desenvolvimento dos sujeitos ocorre não somente devido as suas estruturas biológicas ou fatores externos que determinam o comportamento, mas constrói-se a partir da apropriação dos elementos produzidos culturalmente que, por sua vez, criam novos processos psicológicos (Vygotsky, 1991). Tomando como base a Psicologia Histórico-Cultural, neste estudo, foram utilizados os conceitos de vivência e projeto de vida.

De acordo com a Psicologia Histórico-Cultural, as vivências correspondem às relações estabelecidas entre os processos psíquicos individuais e o meio social, e relacionam-se às interpretações que os sujeitos elaboram sobre as experiências que, na sua trajetória, produzem um efeito marcante (Marques, \& Carvalho, 2014). Nessa elaboração, as vivências agregam conteúdos racionais e emotivos, e atuam como unidade de análise entre a consciência e o meio, que ao longo do desenvolvimento vão se modificando e se complexificando, operando como meio para o processo de tomada de consciência por parte dos sujeitos (Souza, \& Andrada, 2013).

Para Vigotski, as vivências representam um conceito central para a compreensão da relação do sujeito com o mundo, durante todo o ciclo vital, sendo que cada situação social do desenvolvimento vai compreender características diversificadas para os diferentes sujeitos que a experienciam. As vivências correspondem a interpretações sobre uma determinada situação objetiva que os sujeitos apreendem e se posicionam cognitiva e afetivamente, e a partir disso tomam consciência sobre a situação (Toassa, \& Souza, 2010). Nesta relação, a vivência norteará o desenvolvimento psicológico do sujeito, uma vez que ele modifica sua atitude e compreensão acerca da situação experienciada (Silva, 2015). Em relação aos jovens, as vivências que impulsionarão o desenvolvimento estão relacionadas à formação do pensamento por conceitos, o qual possibilita aos jovens expandirem o conhecimento acerca da realidade e sobre si mesmos, tomar consciência acerca dos processos que constituem os fenômenos e posicionar-se diante deles. Além destes aspectos, o pensamento por conceitos amplia a capacidade dos jovens de planejamento de suas atividades e interesses, característica essencial para a construção de seus projetos de vida (Toassa, \& Souza, 2010; Leal, \& Mascagna, 2016).

O conceito de projeto de vida para a Psicologia Histórico-Cultural corresponde a uma das questões centrais do desenvolvimento dos jovens, e está relacionado à formação profissional e à busca de autonomia na atividade de trabalho e em outras esferas da sua vida, tais como as relações sociais e afetivas (Abrantes, \& Bulhões, 2016). A construção do projeto de vida exige uma ação consciente por parte do jovem, que deve estabelecer objetivos e metas a curto, médio 
e longo prazos. Nessa construção, inicialmente, o projeto de vida representa um plano ainda idealizado, que vai se consolidando na medida em que o jovem vai tomando consciência acerca das possibilidades concretas de sua realização (Leal, \& Mascagna, 2016). É a partir das vivências que os sujeitos vão construindo seus projetos de vida, sendo esta uma construção dinâmica que envolve o contexto social, cultural e econômico, e corresponde a uma trajetória, que é planejada, avaliada e reorganizada pelos sujeitos (Maia, \& Mancebo, 2010).

A construção do projeto de vida vai depender da qualidade das mediações ofertadas aos sujeitos durante sua elaboração. Sendo assim, a participação de outros atores nesse processo revela-se de fundamental importância, na medida em que estes podem organizar um conjunto de ações visando a promoção do desenvolvimento e a formação omnilateral dos jovens (Martins, 2016). A formação omnilateral refere-se ao processo de constituição dos sujeitos, na perspectiva do desenvolvimento integral, em superação à formação unilateral proporcionada pelo modelo de produção capitalista que aliena os sujeitos. Considera então, a união entre o processo educativo e a atividade de trabalho realizados na perspectiva da emancipação humana, da consciência das relações construídas pela sociedade e na potencialidade da transformação da realidade (Leal, \& Mascagna, 2016).

Nesse sentido, compreende-se que as medidas socioeducativas devem oferecer aos jovens, possibilidades para a construção de seus projetos de vida por meio da oferta de um conjunto de ações organizadas intencionalmente, voltadas para um trabalho pedagógico que impulsione o seu desenvolvimento integral, considerando os seus interesses. Dessa forma, parte-se do pressuposto que as garantias desses elementos durante a medida socioeducativa devem contribuir para a construção do projeto de vida dos jovens, no entanto, as vivências no cumprimento da MSE mostram que tais elementos não têm sido ofertados de modo suficiente para que os jovens possam efetivá-los, permanecendo um projeto de vida idealizado.

\section{Método}

\section{Participantes}

A pesquisa foi realizada com dez jovens que cumpriam medida socioeducativa de internação em uma instituição de meio fechado em um município do estado da Paraíba. O critério de seleção dos jovens foi a participação destes em um projeto de extensão, promovido no ano anterior à coleta de dados, pelo Núcleo de Pesquisas e Estudos sobre o Desenvolvimento da Infância e Adolescência (Nupedia), vinculado ao Departamento de Psicologia da Universidade Federal da Paraíba. Os jovens entrevistados tinham idades entre 15 e 17 anos e cumpriam a MSE entre um e dois anos.

Foram atribuídos nomes fictícios aos jovens, objetivando garantir o sigilo e anonimato aos participantes da pesquisa. A escolha dos nomes foi inspirada no romance Capitães da areia (Amado, 2009), a partir da semelhança entre as histórias de vida dos jovens entrevistados e dos personagens da obra literária.

\section{Instrumento}

O instrumento utilizado com os jovens foi uma entrevista aberta, realizada individualmente. A entrevista compreendia temas norteadores, contemplando questões sobre as atividades realizadas pelos jovens durante o cumprimento da medida socioeducativa; projetos de vida dos jovens; aspectos presentes no cumprimento da medida socioeducativa para a construção do projeto de vida; os sentidos produzidos pela experiência de cumprimento da medida socioeducativa e a relação como os profissionais no cumprimento da MSE.

\section{Procedimentos de coleta e análise de dados}

Foram cumpridos todos os preceitos éticos pertinentes à pesquisa com seres humanos, conforme a Resolução no 466/2012 do Conselho Nacional de Saúde, vigente à época da pesquisa. Após a aprovação do comitê de ética, obtida por meio do Certificado de Apresentação para Apreciação Ética (CAAE) $n^{\circ}$ 51438715.4.0000.5188, foi solicitada a autorização à Fundação Desenvolvimento da Criança e do Adolescente (Fundac/PB), órgão responsável pela oferta e execução das medidas de meio fechado no estado da Paraíba. O objetivo da pesquisa foi explicado aos dez jovens, que aceitaram participar das entrevistas. O Termo de Consentimento Livre e Esclarecido foi assinado pelos diretores da instituição de MSE, responsáveis pelos jovens. As entrevistas foram gravadas, 
transcritas e posteriormente analisadas a partir da Análise Temática de Conteúdo (Minayo, 2014).

Inicialmente foi realizada uma leitura flutuante do material coletado, seguindo-se a codificação e categorização dos dados e, ao final, a interpretação dos dados à luz do referencial teórico adotado. A análise dos dados revelou as seguintes categorias temáticas: Atividades realizadas no cotidiano do cumprimento da medida socioeducativa; Participação da família; Relações dos jovens com os profissionais; Vivências significativas durante o cumprimento da medida socioeducativa; e Planos para o futuro.

\section{Resultados e Discussão}

\section{Atividades realizadas no cotidiano do cumprimento da MSE}

Ao serem questionados sobre o cumprimento da medida socioeducativa de internação, os jovens fizeram referências às atividades realizadas no cotidiano do cumprimento da MSE. No que se refere a essas atividades, foram observadas as categorias: Escola, Oficinas ocupacionais e pedagógicas, Cursos Profissionalizantes e Recreação.

Esse cotidiano é composto por uma rotina que envolve horários estabelecidos para acordar, realização de higiene pessoal, alimentação, escola e atividades de caráter recreativo que são destinadas a todos os jovens e outras atividades que são ofertadas apenas para alguns deles, de acordo com alguns critérios preestabelecidos ou limitações institucionais, como a formação profissional e oficinas ocupacionais e pedagógicas.

A escola compõe uma das atividades obrigatórias determinadas no Sinase, mas que na execução da MSE não tem sido ofertada de modo satisfatório, tendo em vista que os jovens a frequentam em horário reduzido. Não obstante, a participação em oficinas ocupacionais e pedagógicas não foi apontada por todos eles, tendo em vista que a instituição oferece um número limitado de atividades que não corresponde ao número de jovens internos. Algumas das oficinas pedagógicas mencionadas correspondiam a projetos de instituições da sociedade, como universidades, o que apesar de demonstrar a insuficiência por parte da gestão governamental em relação à existência de atividades, representa a tentativa da unidade de MSE em ampliar a oferta de ações e de estabeleci- mento de parcerias e articulações com a rede de instituições existentes no território, atendendo também o princípio da incompletude institucional preconizado no Sinase.

De forma similar, se caracterizam os cursos profissionalizantes, ofertados de forma insuficiente diante do número de jovens aptos a cursá-los de acordo com os critérios institucionais, fazendo surgir uma fila de espera dos que desejam obter uma formação profissional, significada como possibilidade de aprendizagem, de capacitação para o trabalho e mudança de vida. Já no que se refere ao atendimento técnico, os jovens apontaram sua importância durante o cumprimento da MSE, refletindo, porém, que o acesso a este é difícil, pois tem ocorrido a partir de encontros restritos.

O momento de recreação foi identificado como possibilidade de sair dos quartos em que os jovens permanecem grande parte do dia, trancados. Sendo assim, as atividades de recreação funcionam muito mais como atenuação do sofrimento pela privação da liberdade, do que um conjunto de atividades direcionados ao lazer enquanto direito dos jovens.

De forma geral, os jovens se referiam ao cotidiano na instituição a partir de uma rotina repetitiva e monótona, a qual não produzia novos interesses, como demonstrado na fala de um deles: "Aqui? É sempre a mesma coisa, colégio de manhã, só uma hora e meia de colégio só, e depois banho de sol e pronto. Lá dentro fica só, diversão lá dentro é televisão, dominó, só esses negócios mesmo" (Augusto, 17 anos).

Essa característica da MSE revela a ausência de um projeto pedagógico real na execução da MSE que seja capaz de responsabilizar o jovem e promover o seu desenvolvimento, por meio de um conjunto de ações organizadas e ofertadas a partir de uma intencionalidade. Considera-se aqui a responsabilização do jovem a partir da efetivação da proposta pedagógica da socioeducação distanciada das práticas punitivas, culpabilizantes e violadoras de direitos humanos que tem caracterizado historicamente as políticas de atendimento aos jovens autores de atos infracionais. Nesse sentido, a responsabilização deve ser realizada a partir de seu caráter educativo, ao promover direitos e outras possibilidades de construção e efetivação de projetos de vida distanciados da trajetória infracional (Costa, 2015; Veronese, 2015).

No entanto, o que os dados mostram é a realização de um conjunto de atividades de caráter genérico, cujo objetivo é ocupar o tempo em que os 
jovens permanecem ociosos na instituição. Sendo assim, as atividades disponibilizadas no cotidiano da MSE não têm proporcionado as condições necessárias para que os jovens se desenvolvam, sendo que estes refletem que a oferta das atividades tem sido restrita, apesar das tentativas de ampliação com as instituições parceiras, e as que produziam interesse nos jovens, tais como a inserção em cursos profissionalizantes, são ofertadas de maneira limitada, sendo que a vivência apreendida é a de uma expectativa não atendida (Silva, 2015; Pimentel, Rodrigues, \& Silva, 2016).

A ausência de um projeto pedagógico, a realização de atividades de caráter genérico com a função de ocupar o tempo dos jovens traz como consequências a redução do trabalho a atividades técnico-burocráticas, resumidas na realização de relatórios técnicos, e a realização e encaminhamentos para a rede de atendimento ou espaços educacionais e profissionalizantes que não são desempenhados a partir de uma perspectiva de ação pedagógica transformadora (Oliveira et al., 2015).

A simples inserção no quadro de atividades da instituição não pode ser confundido com o trabalho pedagógico que deve nortear a ação socioeducativa promovendo a responsabilização dos jovens por meio da reflexão sobre suas histórias e a proposição de um projeto de vida (Souza, \& Costa, 2012). Tomando-se como base os pressupostos da Psicologia Histórico-Cultural, compreende-se que a realização do trabalho pedagógico deve guiar-se pela organização de ações pautadas na intencionalidade do desenvolvimento integral humano, buscando a formação omnilateral dos sujeitos, sendo esta relacionada com o desenvolvimento da consciência da realidade e das possibilidades de transformação (Martins, 2016). Nesse processo, as vivências constituem-se como elementos centrais para a tomada de consciência e para direcionar o desenvolvimento dos jovens. No entanto as atividades ofertadas não têm se apresentado como esses elementos necessários para o desenvolvimento integral, sendo as vivências apreendidas como atividades repetitivas que não representam possibilidades de mudança (Silva, 2015).

\section{Participação da família}

No tema participação da família, foram observadas as categorias Visita Familiar e Auxílio da família no cumprimento da MSE. A visita familiar ocorre em determinados horários da semana, estabelecidos pela unidade de MSE. Os jovens expressaram a importância da participação da família para o cumprimento da MSE de internação, por exercer a função de suporte e alívio, assim como a possibilidade de ter o contato com a realidade fora da instituição. Além disso, refletem sobre o pouco tempo destinado à visita familiar, o que implica dizer que, embora a instituição disponibilize dias e horários específicos para essa atividade, estes têm sido insuficientes para garantir a convivência familiar.

Em relação à visita familiar, essa participação enfrenta obstáculos diante das dificuldades experienciadas pelas famílias, seja em razão da distância de seus locais de moradia para a instituição de MSE ou por dificuldades relacionadas a sua condição financeira. Além desses fatores, a família enfrenta obstáculos institucionais ao ser submetida, durante a visita familiar, à revista íntima vexatória, regulamentada pela instituição. Esse procedimento é visto pelos jovens como humilhação e, em alguns casos, tem impedido a participação da família, que se recusa a passar pelo procedimento, como se pode observar na fala do jovem: "Minha irmã num quer vim me visitar não, por causa que ela disse que num gosta de passar pela humilhação ali na frente não" (João Grande, 17 anos).

Tais dados apontam que a participação da família não tem se caracterizado pelo exercício da garantia dos direitos dos jovens, revelando ainda a forte culpabilização das famílias submetidas ao procedimento de revista íntima vexatória. Esse procedimento revela que as famílias e jovens vivenciam um processo que os coloca em constante suspeição. Tal situação é discutida na literatura como a permanência da criminalização da juventude negra e pobre, identificada como o segmento que mais tem recebido e cumprido as MSE, apesar de não serem os únicos a praticar atos infracionais (Jimenez, \& Frasseto, 2015). Esses jovens são culpabilizados pelo aumento dos índices de violência, sendo que essa associação tem fortalecido os pedidos por parte da sociedade pela redução da maioridade penal e também pelo aumento do tempo da medida de internação (Morais, \& Malfitano, 2013).

Associado a isso, verifica- se que os discursos que culpabilizam as famílias situam-na como responsáveis pela prática dos atos infracionais pelos jovens, sendo estas apontadas como um fator de risco para a prática de atos infracionais (Nardi, \& Dell'Aglio, 2013). 
Essa discriminação se concretiza nas práticas citadas durante os procedimentos da visita familiar às unidades de cumprimento da MSE. Esses obstáculos impostos à participação da família no cumprimento da MSE trazem consequências para o desenvolvimento dos jovens em razão do afastamento familiar, que já é agravado pela institucionalização e pelas dificuldades impostas às visitas (Medeiros, \& Paiva, 2015).

Com relação ao auxílio da família no cumprimento da MSE, os jovens fizeram referência ao alívio que a participação da família traz, denotando que a MSE se caracteriza por um sofrimento imposto a eles, que têm nesses momentos a possibilidade de amenizá-lo com o suporte familiar. A função de auxílio e alívio tem sido identificada por outros autores, os quais identificaram que a participação das famílias representa o elemento para que os jovens continuem cumprindo a MSE, sendo que a família também é o ponto de apoio para quando o jovem sair da instituição de internação, visto que esses jovens veem a família como motivação e suporte para o afastamento dos atos infracionais (Silveira et al., 2015; Souza, \& Costa, 2012; Yokomiso, 2013).

Esses aspectos mostram que o direito à participação da família durante o cumprimento da MSE não está sendo garantido. Os relatos dos jovens evidenciam que as vivências na MSE não têm se constituído a partir da efetiva participação das famílias, comprometendo os direitos relacionados à visita familiar e a função de auxílio durante o cumprimento da MSE. O que por sua vez traz implicações para o desenvolvimento dos jovens, tendo em vista que pode comprometer a construção do seu projeto de vida na medida em que a não efetivação da participação pode contribuir para o afastamento da família e vai na contramão do fortalecimento da convivência familiar (Toassa, \& Souza, 2010).

\section{Relações dos jovens com a equipe de profissionais}

A vivência no cumprimento da MSE também é referida pelos jovens pelas relações estabelecidas com os profissionais da instituição. Destacaram-se nas falas dos jovens as Relações com os agentes socioeducativos e as Relações com a equipe técnica da instituição.

Os jovens expressaram que a relação com os agentes socioeducativos é marcada pelo autoritarismo, em que estes últimos exercem um poder sobre eles, restando-lhes a obediência às normas institucionais. No entanto, sinalizam que parte dos agentes socioeducativos não cumprem tais normas, revelando a existência de práticas corruptas dentro da instituição. Como consequência, os jovens se submetem a essas regras paralelas, evitando serem punidos novamente por meio da medida disciplinar existente na instituição.

Observa-se também que a submissão dos jovens se reflete na negociação de um "bom comportamento", que será registrado em sua ficha que será submetida à avaliação judicial. O depoimento de um deles demonstra essa relação de submissão: "Sobre os agentes [socioeducativos] assim, né muito bom não né. [...] Mai eu num procuro se prejudicar não, num tem, que eu sei que minha situação já num é boa. Aí eu também num quero se prejudicar né" (Ezequiel, 16 anos).

Souza e Costa (2012) problematizam a existência dessa cultura nas instituições privativas de liberdade, em que o cumprimento das normas, o bom comportamento dos jovens e a frequência nas atividades são designadas como meios para resistir dentro da instituição, assim como funcionam como meios para obter a extinção da MSE. Tais artifícios estão longe de possibilitar a responsabilização e a reflexão por parte dos jovens.

Percebe-se ainda, nessa relação, a ausência de uma atividade pedagógica por parte dos agentes socioeducativos, que têm executado muito mais procedimentos de segurança e vigilância dentro da instituição. Pimentel et al. (2016) identificaram que os agentes socioeducativos que compõem o quadro de funcionários das unidades de internação têm a formação de agente de segurança e reproduzem, nas instituições socioeducativas, ações permeadas pela violência. Reiterando esse quadro, há a falta de uma ação pedagógica definida para esses profissionais, assim como a ausência de capacitações que promovam discussões acerca dos direitos humanos de crianças, jovens e suas famílias, e do desenvolvimento de atividades capazes de promover o desenvolvimento dos jovens.

As relações com a equipe técnica da instituição foram descritas pelos jovens a partir dos atendimentos prestados e caracterizados por estes pela função de proporcionar alívio e realizar aconselhamento durante o cumprimento da MSE. O depoimento de Barandão representa a função do atendimento técnico na instituição: 
Aqui só quem conversa comigo mesmo é a assistente social e a psicóloga. É bom, a pessoa, elas faz uma conversa com a pessoa para pessoa ficar mais aliviado né, e tem conselho bom né. Pelo menos é uma pessoa que chega assim e dá um conselho bom, a pessoa. Ali, quando ela chama a pessoa pra conversar, a pessoa fica mais à vontade, mais aliviado, por que lá dentro é só maldade, e quando a pessoa vem aqui, a pessoa tá mais aliviado (Barandão, 16 anos).

Destaca-se que o atendimento prestado tem se caracterizado pela prática do aconselhamento dos jovens no que diz respeito ao comportamento destes, seja em relação ao cumprimento das normas institucionais, seja em relação aos atos infracionais. Esse formato de atendimento, pautado no modelo clínico individual, foi encontrado, de modo preponderante por Santos e Menandro (2017), em instituições de medida socioeducativa de internação, contrariando as diretrizes legais que norteiam essa política. Embora a prática do atendimento individual por meio do aconselhamento seja capaz de aliviar o sofrimento psíquico, não é capaz de possibilitar mudanças mais significativas na vida dos sujeitos, considerando-se o contexto em que vivem, e tampouco garantir-lhes os direitos (Santos, \& Menandro, 2017).

Esse quadro reflete a ausência de concretização de um projeto pedagógico a ser desenvolvido pelos profissionais da instituição, que possibilite a reflexão dos jovens acerca da realidade, promova sua responsabilização e o atendimento das suas diversas necessidades de modo a realizar um acompanhamento integral (Veronese, 2015). Conforme discute Martins (2016), nem toda ação pedagógica realizada é capaz de promover o desenvolvimento dos sujeitos, sendo que este depende da qualidade das mediações oferecidas, e que no contexto da internação tem se revelado distante desses objetivos.

\section{Vivências significativas durante o cumprimento da MSE}

Em relação às vivências significativas durante o cumprimento da MSE de internação, foram identificadas as categorias: Reflexão, Afastamento dos atos infracionais, Revolta, Recuperar e Deixar de usar drogas. Alguns jovens evidenciaram a possibilidade de refletir sobre sua história de vida e sobre o ato infracional, sendo esta reflexão proporcionada pelo tempo em que permanecem nos quartos e não facilitada pela intervenção de um profissional. De modo semelhante, nas falas dos jovens emerge a contribuição da MSE de internação possibilitar o afastamento dos atos infracionais, tendo em vista que os jovens estão cerceados pelos limites físicos da instituição. Como consequência, esse afastamento tem se caracterizado pela função de proteção da vida, pois o fato de estarem em uma instituição fechada os afasta das ameaças sofridas na sua história de vida, como revelado no depoimento do jovem Almiro: "Ajuda, tá ajudando muito... se eu tivesse no mundão agora, eu podia tá contando isso aqui pra vocês? Não, eu podia tá morto... podia tá por aí, fazendo o que eu tava fazendo né? Aqui não, aqui eu tô preso, mas tô vivo" (Almiro, 17 anos).

Esse afastamento, no entanto, revela-se temporário, dado que está circunscrito na execução da MSE e, por não ser aliado a uma intervenção pedagógica, revela-se insuficiente. A reflexão sobre o desejo de afastar-se dos atos infracionais é também mencionada como uma consequência da MSE, pois os jovens declaram que não querem voltar para a instituição de internação, tendo em vista a forma como se caracterizou a medida de privação da liberdade e suas repercussões.

A MSE tem sido significada pelos jovens como algo sem importância quando relacionada à possibilidade de contribuição e, no caso da internação, ela tem provocado sentimento de revolta sobre as experiências vivenciadas em seu cotidiano da MSE, agregados ao sentimento de injustiça, relacionados à retirada da liberdade e à ociosidade que vivenciam. Os jovens entrevistados fizeram menção à experiência do tempo de cumprimento, realizando avaliações sobre a MSE, apontando suas restrições e seu caráter prisional, e questionando para que tem servido a execução da MSE. Em suas falas, os jovens demonstram que a MSE de internação não exerce uma função pedagógica, destacando apenas o caráter punitivo e, portanto, não visualizam a possibilidade de uma mudança de vida. Aliado a isso, refletem que a MSE é determinada de forma genérica, em que a aplicação da medida varia entre seis meses, podendo chegar até três anos. Os jovens apontaram para um sentimento de perda da juventude, resultante da privação de liberdade que limita suas experiências ao que é ofertado pela instituição. O que sobressai é a função punitiva da MSE de internação que reproduz o modelo prisional adulto 
por meio da violência institucional e da restrição de diversos direitos, tais como o de receber visitas de seus familiares (Souza, \& Costa, 2012).

Desse modo, os jovens questionam a função da MSE que lhes é aplicada, compreendendo que ela deveria ser efetivada de modo a oferecer outras possibilidades, mas que o caráter socioeducativo não tem sido executado, destacando-se um conjunto de práticas cujo foco é a disciplina sobre o seu comportamento, como é destacado na fala a seguir:

Povo diz que aqui é... como é, que tem aí na frente o nome? Socioeducativo né? Oxe! Pergunta o que é ensinado aqui pra nós ser educado, pode perguntar até ao diretor, o que é ensinado a ser educado aqui, ensina nada não, só a ficar de cabeça baixa, é a educação deles (Gringo, 17 anos).

Alguns jovens revelaram a necessidade de a instituição articular com a rede de proteção e garantia dos direitos da infância e juventude para receberem medidas protetivas de vida ao saírem da instituição por estarem ameaçados em seus bairros de origem. Nesse caso, questões relacionadas à própria sobrevivência e à sobrevivência da família colocam-se como imediatas, adiando-se outras dimensões do projeto de vida que estejam relacionadas à autonomia desses jovens. Para os jovens que se encontram ameaçados, o desejo de exercer uma atividade profissional vincula-se necessariamente às condições de sobrevivência em que se busca auxílio financeiro e em que se responsabilizam pela mudança das condições de vida de sua família.

Outro ponto mencionado pelos jovens são contribuições compreendidas como positivas por estes e que se referem à possibilidade de a MSE poder "recuperar os jovens", ou seja, de possibilitar uma nova trajetória de vida não vinculada aos atos infracionais e à possibilidade de deixar de usar drogas, já que umas das regras da instituição é a proibição do uso de drogas lícitas e ilícitas. Mais uma vez, percebe-se que essa contribuição é provisória, ocasionada pela falta de acesso dos jovens à droga e imposta como consequência de uma restrição do direito de ir e vir, em que não são priorizadas estratégias de cuidado pautadas na redução de danos e na promoção de saúde (Vicentin, 2016).

A noção de recuperabilidade/irrecuperabilidade coloca exclusivamente no jovem a responsa- bilidade pela mudança de vida e rompimento com a trajetória infracional. Essa forma de tratamento individualiza a questão, centralizando os motivos que repercutiram no ato infracional, no comportamento do jovem, que é visualizado a partir do diagnóstico do infrator, violento e com o prognóstico de que não é possível ser recuperado, desviando-se a atenção para a ineficiência das medidas socioeducativas (Souza, \& Costa, 2012).

A redução da MSE ao cumprimento da disciplina não proporciona condições para que os jovens sejam responsabilizados, tampouco possam visualizar outras possibilidades para suas vidas e, assim, construir seus projetos de vida, pois, apesar de apontarem algumas contribuições durante a internação, estas não têm correspondido ao conjunto de atividades organizadas intencionalmente e necessárias para a promoção do desenvolvimento omnilateral dos jovens (Souza, e Costa, 2012; Martins, 2016). A partir das vivências, os jovens realizam interpretações, posicionando-se de forma emotiva e racionalmente e, a partir disso, identificam que o cumprimento da MSE produz sentimentos de revolta diante do que é experienciado e a reflexão de que não querem ser submetidos novamente à aplicação de uma medida socioeducativa, pois esta é identificada como uma experiência punitiva e que pouco tem contribuído para a mudança de vida (Toassa, \& Souza, 2010). Como as vivências operam como meios para o processo de tomada de consciência, ao refletirem e se posicionarem sobre a medida socioeducativa, os jovens passam a reconhecer os limites da sua execução e o que necessitam que lhes seja ofertado durante o cumprimento e após a extinção da MSE, para que pudessem construir seus projetos de vida (Souza, \& Andrada, 2013). No entanto, as vivências no cumprimento da MSE têm sido construídas a partir de experiências negativas ou da ausência de ferramentas que os auxiliassem, processos esses resultantes de ações contraproducentes aos objetivos da socioeducação (Oliveira et al., 2015).

\section{Planos para o futuro e implicações da medida socioeducativa para o projeto de vida}

Os jovens em cumprimento de MSE expressaram desejos relacionados aos seus planos para o futuro, identificados através das categorias: Mudança de Vida, Formação Profissional e Trabalho, Conclusão 
dos estudos e Convivência familiar. Esses planos são delineados para serem executados após o cumprimento da MSE e distantes da instituição, sendo que, no momento do cumprimento, tais planos são referenciados apenas no campo da idealização. Nesses planos são esboçados o desejo por uma mudança de vida distanciada dos atos infracionais e do uso de drogas. Os jovens visualizam a formação profissional e o trabalho aliados à conclusão dos estudos como possibilidades para o afastamento dos atos infracionais e realização dos projetos de vida distanciados dos atos infracionais. Em relação à convivência familiar, os jovens referem-se ao retorno à família de origem ou à constituição de uma nova família, como representado na fala a seguir:

Eu imagino ficar com minha família, né. Mudar de vida e, aproveitar por enquanto que minha mãe e meu pai tá vivo né... E trabalhar né, pra sustentar minha família e ficar com eles. Arrumar uma mulher né, quando chegar na rua... eu penso em trabalhar com o meu pai, que eu já aprendi muitas coisas com ele, já. E aceitar alguma coisa que ele tem. E fazer uns curso no Senai né, pá aprender mais coisa. Eu queria de construção civil (João José, 17 anos).

Na reflexão sobre o projeto de vida, as vivências atuais representam passos importantes para a construção. No que se refere à MSE de internação, as experiências vão se caracterizar como vivências relacionadas a uma oportunidade, principalmente quando relacionadas à possibilidade de concluir um curso profissionalizante, em que os jovens refletem que não teriam essa oportunidade fora da instituição. Outros jovens, porém, que não tiveram acesso a essa formação durante o cumprimento da MSE, seja pela idade incompatível ou por não existirem vagas suficientes, consideram que a MSE não ajuda a construir projetos de vida, como refletido na fala de Augusto: "Oxe, ajuda não. Não, aqui dentro não. É, podia né? Aí tem uns cursos aí também, mas eu não tô, botaram meu nome ainda não, mas tem gente aí nos cursos" (Augusto, 17 anos).

A fala revela que um dos principais elementos que caracterizam os interesses dos jovens, a formação profissional, é responsável por impulsionar o seu desenvolvimento psíquico (Abrantes \& Bulhões, 2016) e não tem sido garantida nas ações da MSE, ficando restrita aos poucos jovens que conseguem acessá-la. Nesse caso, não são oferecidas as condições necessárias para a construção do projeto de vida para todos os jovens que estão cumprindo MSE, o qual exige uma organização por parte do jovem ao planejá-lo, de acordo com o que lhe é disponibilizado (Maia, \& Mancebo, 2010). Além disso, mesmo para os que conseguem realizar um curso profissionalizante, este não é articulado com políticas de inserção profissional ou geração de renda, o que pode afetar suas possibilidades após o cumprimento da MSE, pois os jovens não conseguem visualizar os passos necessários para efetivação do projeto de vida, o que pode se traduzir nas incertezas diante do futuro e na inserção precária no mercado de trabalho informal (Leal, \& Mascagna, 2016).

O fato de expressarem seus projetos de vida apenas para quando saírem da instituição revela a falta de conexão entre as atividades ofertadas na instituição de MSE enquanto facilitadora na construção deste projeto, pois o que os jovens têm vivenciando no cumprimento da medida socioeducativa não se aproxima dos planos que estes têm esboçado para si e para suas famílias. Contrariamente, o que os jovens visualizam como perspectiva mais próxima para efetivar seu projeto de vida é a possibilidade de retornar ao convívio familiar ou de constituir sua própria família. Paradoxalmente, como refletido em suas falas, a participação familiar durante o cumprimento da MSE não tem sido garantida da forma como se determina nos marcos legais do ECA e do Sinase, comprometendo as vivências relacionadas ao direito a convivência familiar e, por sua vez, repercutindo na construção do projeto de vida durante o cumprimento da MSE (Silva, 2015).

Dessa forma, os dados apresentados nesse artigo mostram que as vivências oportunizadas no cumprimento das MSE não têm contribuído para a construção do projeto de vida dos jovens, pois a MSE não tem ofertado e garantido às condições necessárias para a construção de um plano que deve ser organizado, avaliado e de acordo com o que experienciado. As vivências durante o cumprimento da MSE têm sido apreendidas a partir de ações pontuais e fragmentadas, o que compromete a qualidade das mediações, e os elementos oferecidos não têm sido suficientes para promover o desenvolvimento omnilateral dos jovens (Martins, 2016). 
As ações empreendidas distanciam-se de uma função pedagógica e não estão organizadas em um conjunto complexo que atenda os aspectos estabelecidos como necessidades e interesses dos jovens, e que poderiam ser potencializadoras do desenvolvimento (Leal, \& Mascagna, 2016). Nesse sentido, como esses elementos não têm sido garantidos em sua completude, o projeto de vida dos jovens se mantém como um plano idealizado e distante das possibilidades concretas de consolidação.

\section{Considerações finais}

A partir da análise realizada, pode-se compreender que as vivências no cumprimento MSE de internação não trazem contribuições para a construção de projetos de vida dos jovens. Os elementos analisados levaram à compreensão de que algumas possibilidades são oferecidas a alguns jovens durante o cumprimento da medida de internação, tais como acesso à escola e inserção em cursos profissionalizantes. Todavia, essas inserções não têm sido oferecidas de modo a potencializar o desenvolvimento desses jovens e promover sua autonomia, seja por sua oferta restrita ou por não oferecer as condições necessárias para o desenvolvimento integral.

Percebe-se, a partir desse estudo, que, em vez de promover uma prática pedagógica voltada para auxiliar o desenvolvimento dos jovens, a MSE de internação tem pautado suas ações na manutenção de práticas punitivas e da não garantia de direitos, sendo reforçada ainda por ações que contribuem com essa lógica por meio da minimização do sofrimento, em vez de combatê-las. Esses aspectos levam a compreensão sobre a ausência da função socioeducativa na aplicação da MSE, evidenciada pela falta de uma intencionalidade pedagógica capaz de promover projetos de vida para os jovens que sejam diferentes das condições que os levaram ao cumprimento da MSE.

Ressalta-se ainda que os jovens esboçam seus projetos de vida e apontam quais aspectos as MSE deveriam lhes oferecer para a sua construção e efetivação, porém nem todos têm a possibilidade de experienciá-los, o que implica que, nas vivências durante o cumprimento da MSE, esses outros elementos punitivos se apresentarão como preponderantes. As vivências durante o cumprimento da medida socioeducativa repercutem na tomada de consciência pelos jovens de que a MSE se caracteriza como uma pena e não como possibilidade de construção do projeto de vida, almejado por estes.

Na realização deste estudo, observou-se que a socioeducação estabelecida pelo Sinase está distante de se concretizar, tanto pela manutenção de práticas punitivas, como pela ausência de um projeto pedagógico que cumpra os objetivos dispostos pela lei. A partir da fala dos jovens, foi possível perceber que as ações realizadas não estão pautadas em um projeto pedagógico que auxilie a construção do projeto de vida.

Conhecer as vivências dos jovens em cumprimento de MSE possibilita reflexões sobre as ações que vêm sendo empreendidas nas unidades de internação e sobre a importância de se oferecer intervenções que visem o desenvolvimento da autonomia dos jovens e das potencialidades das famílias. Dentre as intervenções que possibilitam a construção do projeto de vida dos jovens destaca-se o cumprimento do Plano Individual de Atendimento, respeitando-se os interesses dos jovens, as possibilidades de realização das atividades, durante o cumprimento da MSE e o planejamento do futuro, considerando a participação das famílias. Além disso, destaca-se a importância da permanente articulação entre as políticas sociais e a rede de instituições presentes nos territórios de atuação das equipes das unidades de MSE visando a efetivação da garantia dos direitos, a oferta de atividades que promovam o desenvolvimento desses jovens, a partir da perspectiva do princípio da incompletude institucional e participação e colaboração de diferentes atores.

Considera-se que informações mais complexas acerca do funcionamento das MSE podem ser fornecidas pelos familiares dos jovens e profissionais que executam a socioeducação, pois estes são mediadores no processo de construção do projeto de vida dos jovens. Quanto aos familiares, revela-se que, no projeto de vida dos jovens a família constitui um dos elementos principais, desse modo, torna-se fundamental ouvi-las, considerar suas necessidades e promover ações para o fortalecimento dos vínculos familiares. Quanto aos profissionais, destaca-se a importância de analisar como estes compreendem a sua atividade junto às MSE, e de que forma podem contribuir com a construção do projeto de vida dos jovens e o que necessitam para mediar as garantias de tais direitos. 


\section{Referências}

Abrantes, A. A., \& Bulhões, L. (2016). Idade adulta e o desenvolvimento psíquico na sociedade de classes: Juventude e trabalho. In L. M. Martins, A. A. Abrantes, \& M. G. D. Facci (Orgs.), Periodização histórico-cultural do desenvolvimento psíquico: Do nascimento à velhice (pp. 241-265). Campinas, SP: Autores Associados.

Alencar, V. (2014). Considerações acerca da lei do sinase. In I. L. Paiva, C. Souza, \& D. B. Rodrigues (Orgs.), Justiça juvenil: Teoria e prática no sistema socioeducativo (pp. 49-58). Natal, RN: EDUFRN.

Amado, J. (2009). Capitães da areia. São Paulo, SP: Companhia das Letras.

Baquero, R. V. A., Lemes, M. A. \&, Santos, E. A. (2011). Histórias de vida de jovens egressos de medidas socioeducativas: entre a margem e a superação. Educação, 34(3), 341-350.

Barone, R. E. M. (2016). Adolescente em liberdade assistida, capacitação para o trabalho e inserção socioprodutiva. In C. A. C. Filgueiras, \& R. Medeiros (Orgs), Jovens, trabalho e políticas públicas: Anseios e desafios (pp. 139-166). Belo Horizonte, MG: PUC Minas.

Barone, R. E. M., \& Silva, A. M. (2015). Adolescente em cumprimento de medida socioeducativa, capacitação para o trabalho e inserção no mundo do trabalho: Desafios no contexto de unidades de privação de liberdade. Revista da Faculdade de Educação, 24(2), 155-176.

Costa, C. (2015). Dimensões da medida socioeducativa: Entre o sancionatório e o pedagógico. Textos \& Contextos, 14(1), 62-73. https://doi.org/10.15448/1677-9509.2015.1.16858

Ferraz, J. D. F., Castro, J. L. P., Jr, Vieira, F. O., \& Cordeiro, W. (2011). O funcionamento do programa de proteção a crianças e adolescentes ameaçados de morte (PPCAAM) nas áreas de vulnerabilidade social no Rio de Janeiro. Revista de Políticas Públicas, 15(2), 277-286.

Jimenez, L., \& Frasseto, F. A. (2014). Face da morte: A lei em conflito com o adolescente. Psicologia \& Sociedade, 27(2), 404-414. https://doi.org/10.1590/1807-03102015v27n2p404

Leal, Z. F. R. G., \& Mascagna, G. C. (2016). Adolescência: Trabalho, educação e a formação omnilateral. In L. M. Martins, A. A. Abrantes, \& M. G. D. Facci, (Orgs.), Periodização histórico-cultural do desenvolvimento psíquico: Do nascimento à velhice (pp. 221-237). Campinas, SP: Autores Associados.

Lei $N^{\circ}$ 8.069, de 13 de julho de 1990. Dispõe sobre o Estatuto da Criança e do Adolescente e dá outras providências.

Lei No 12.594, de 18 de janeiro de 2012. Institui o Sistema Nacional de Atendimento Socioeducativo (Sinase), regulamenta a execução das medidas socioeducativas destinadas a adolescente que pratique ato infracional; e altera as Leis n. 8.069, de 13 de julho de 1990 (Estatuto da Criança e do Adolescente); 7.560, de 19 de dezembro de 1986, 7.998, de 11 de janeiro de 1990, 5.537, de 21 de novembro de 1968, 8.315, de 23 de dezembro de 1991, 8.706, de 14 de setembro de 1993, os Decretos-Leis n. 4.048, de 22 de janeiro de 1942, 8.621, de 10 de janeiro de 1946, e a Consolidação das Leis do Trabalho (CLT), aprovada pelo Decreto-Lei n. 5.452, de $1^{\circ}$ de maio de 1943.

Maia, A. A. R. M., \& Mancebo, D. (2010). Juventude, trabalho e projetos de vida: Ninguém pode ficar parado. Psicologia: Ciência e Profissão, 30(2), 376-389. https://doi.org/10.1590/S1414-98932010000200012

Marques, E. S. A. \& Carvalho, M. V. C. (2014). Vivência e afetação na sala de aula: Um diálogo entre Vigotski e Espinosa. Revista da FAEEBA: Educação e Contemporaneidade, 23(41), 41-50.

Martins, L. M. (2016). Psicologia histórico-cultural, pedagogia histórico-crítica e desenvolvimento humano. In L. M. Martins, A. A. Abrantes, \& M. G. D. Facci (Orgs.), Periodização histórico-cultural do desenvolvimento psíquico: Do nascimento à velhice (pp. 13 -34). Campinas, SP: Autores Associados.

Medeiros, F. C., \& Paiva, I. L. (2015). A convivência familiar no processo socioeducativo de adolescentes em privação de liberdade. Estudos e Pesquisas em Psicologia, 15(2), 568-586.

Melsert, A. L. M., \& Bock, A. M. B. (2015). Dimensão subjetiva da desigualdade social: Estudo de projetos de futuro de jovens ricos e pobres. Educação e Pesquisa, 41(3), 773-789. https://doi.org/10.1590/S1517-9702201507135302

Minayo, M. C. S. (2014). O desafio do conhecimento: Pesquisa qualitativa em saúde (14a ed.). São Paulo, SP: Hucitec.

Morais, A. \& Malfitano, A. P. S. (2013). Adolescência e juventude: Entre conceitos, violências e saber técnico. Revista Brasileira Adolescência e Conflitualidade, (9), 48-71. https://doi.org/10.17921/2176-5626.n9p\%25p

Nardi, F. L., \& Dell'Aglio, D. D. (2013). Reflexões acerca do ato infracional e da medida socioeducativa: Estudos de caso. Revista Interamericana de Psicología, 47(1), 33-42. https://doi.org/10.30849/rip/ijp.v47i1.199 
Oliveira, C. B. E., Oliva, O. B., Arraes, J., Galli, C. Y., Amorim, G. G., \& Souza, L. A. (2015). Socioeducação: Origem, significado e implicações para o atendimento socioeducativo. Psicologia em Estudo, 20(4), 575-585. https://doi. org/10.4025/psicolestud.v20i4.28456

Oliveira, J.V., Voltolini, L., \& Costa, M. C. L. (2016). Por trás das grades: A educação escolar para adolescentes privados de liberdade. Ensino \& Pesquisa: Revista Multidisciplinar de Licenciatura e Formação Docente, 14(1), 106-122.

Paiva, I. L., \& Cruz, A. V. H. (2014). A psicologia e o acompanhamento de adolescentes em conflito com lei. In I. F. Oliveira, \& O. H. Yamamoto (Orgs.), Psicologia e políticas sociais: Temas em debate (pp. 175-214). Belém, PA: UFPA.

Pimentel, E., Rodrigues, N., \& Silva, R. A. (2016). A prisionização de agentes de segurança socioeducativos das unidades de internação da superintendência de assistência socioeducativa (Sase) em Maceió e seus efeitos sobre a execução da medida socioeducativa de internação. Revista da ESMAL, (1), 275-297.

Ritter, C. (2010). O mercado de trabalho para o adolescente em conflito com a lei: A economia solidária como alternativa de inserção em Santo Ângelo (Dissertação de mestrado). Pontifícia Universidade Católica do Rio Grande do Sul, Porto Alegre, RS, Brasil.

Santos, M. N., \& Menandro, M. C. S. (2017). Atuação profissional junto aos adolescentes em medida socioeducativa de internação: Um estudo com psicólogos. Interação em Psicologia, 21(2), 107-117. https://doi.org/10.5380/psi. v21i2.34081

Silva, M. L. M. B. (2015). O materialismo histórico e sua influência na teoria histórico-cultural. Tramas para Reencantar o Mundo, 1(1), 1-10.

Silveira, K. S. S., Machado, J. C., Zappe, J. G., \& Dias, A. C. G. (2015). Projetos futuros de adolescentes privados de liberdade: Implicações para o processo socioeducativo. Psicologia: Teoria e Prática, 17(2), 52-63. https://doi. org/10.15348/1980-6906/psicologia.v17n2p52-63

Souza, V. L. T., \& Andrada, P. C. (2013). Contribuições de Vigotski para a compreensão do psiquismo. Estudos de Psicologia (Campinas), 30(3), 355-365. https://doi.org/10.1590/S0103-166X2013000300005

Souza, L. A., \& Costa, L. F. (2012). O significado de medidas socioeducativas para adolescentes privados de liberdade. Acta Colombiana de Psicología, 15(2), 87-97.

Teixeira, A. R., Oliveira, G. M., Guido, T. C., \& Barone, R. E. M. (2016). Adolescente em liberdade assistida e inserção no mundo do trabalho: Uma análise de ações socioeducativas no município de Osasco, SP. Revista Brasileira Adolescência e Conflitualidade, (14), 37-44. https://doi.org/10.17921/2176-5626.\%25n14p37-44

Toassa, G., \& Souza, M. P. R. (2010). As vivências: Questões de tradução, sentidos e fontes epistemológicas no legado de Vigotski. Psicologia USP, 21(4), 757-779. https://doi.org/10.1590/S0103-65642010000400007

Veronese, J. R. P. (2015). O adolescente autor de ato infracional sob a perspectiva da intersetorialidade. Revista do Direito, 3(47), 125-143. https://doi.org/10.17058/rdunisc.v3i47.6430

Vicentin, M. C. G. (2016). Saúde mental no contexto de privação da liberdade. In: Conselho Regional de Psicologia de São Paulo - CFP/SP, Caderno de debates: Visitas institucionais à Fundação Casa (pp: 24-29). São Paulo, SP: o autor. Recuperado de: http://www.crpsp.org.br/portal/comunicacao/cadernos_tematicos/12/frames/ fr_politica.aspx

Vygotsky, L. S. (1991). A formação social da mente: O desenvolvimento dos processos psicológicos superiores (4a ed.). São Paulo, SP: Martins Fontes.

Yokomiso, C. T. (2013). Família, comunidade e medidas socioeducativas: Os estados psíquicos compartilhados e a transformação da violência (Tese de doutorado). Instituto de Psicologia, Universidade de São Paulo, São Paulo, SP, Brasil.

\section{Cibele Soares da Silva Costa}

Psicóloga. Doutoranda em Psicologia Social e Mestra em Psicologia Social pela Universidade Federal da Paraíba (UFPB), João Pessoa - PB. Brasil.

E-mail: cibele_sscosta@yahoo.com.br

http://orcid.org/0000-0002-7004-2818 


\section{Maria de Fatima Pereira Alberto}

Doutora em Sociologia pela Universidade Federal de Pernambuco (UFPE), Recife - PE. Brasil. Professora Associada IV do Departamento de Psicologia e do Programa de Pós-Graduação em Psicologia Social da Universidade Federal da Paraíba (UFPB), João Pessoa - PB. Brasil. Coordenadora do Núcleo de Pesquisas e Estudos sobre o Desenvolvimento da Infância e da Adolescência (Nupedia). Bolsista de Produtividade em Pesquisa do CNPq - Nível - 2 .

E-mail: jfalberto@uol.com.br

D http://orcid.org/0000-0003-2515-9571

\section{Erlayne Beatriz Félix de Lima Silva}

Psicóloga. Mestra em Psicologia Social pela Universidade Federal da Paraíba (UFPB), João Pessoa - PB. Brasil.

E-mail: erlayne.beatriz@gmail.com

D http://orcid.org/0000-0002-3380-2881

Endereço para envio de correspondência:

Rua Inácio Ramos de Andrade, 62,. Cep: 58052-210. Jardim Cidade Universitária. João Pessoa - PB. Brasil.

Recebido 08/10/2017

Reformulado 02/07/2018

Aceito 07/09/2018

Received $10 / 08 / 2017$

Reformulated $07 / 02 / 2018$

Approved 09/17/2018

Recibido 08/10/2017

Reformulado 02/07/2018

Aceptado 17/09/2018

Como citar: Costa, C. S. S., Alberto, M. F. P., \& Silva, E. B. F. L. (2019). Vivências nas medidas socioeducativas: possibilidades para o projeto de vida dos jovens. Psicologia: Ciência e Profissão, 39, e186311, 1-16.

https://doi.org/10.1590/1982-3703003186311

How to cite: Costa, C. S. S., Alberto, M. F. P., \& Silva, E. B. F. L. (2019). Experiences in socio-educational measures: Possibilities for young people's project of life. Psicologia: Ciência e Profissão, 39, 1-16.

https://doi.org/10.1590/1982-3703003186311

Cómo citar: Costa, C. S. S., Alberto, M. F. P., \& Silva, E. B. F. L. (2019). Vivencias en las medidas socioeducativas: posibilidades para el proyecto de vida de los jóvenes. Psicologia: Ciência e Profissão, 39, 1-16. https://doi.org/10.1590/1982-3703003186311 